\title{
An anatomic anal sphincter-saving procedure for rectal cancers located at anorectal junction
}

\author{
Theodoros Mariolis-Sapsakos ${ }^{1}$, Giannos Psathas ${ }^{2}$, Taxiarchis Konstantinos Nikolouzakis ${ }^{3}$, Konstantinos Laschos ${ }^{4}$, \\ Charikleia Triantopoulou ${ }^{5}$, Gerasimos Bonatsos ${ }^{6}$ and John Tsiaoussis ${ }^{3^{*}}$ id
}

\begin{abstract}
Background: This study aims to present the feasibility of the open approach of hemilevator excision (HLE) as a promising alternative of the laparoscopic and/or robotic ones for the treatment of low rectal cancer extending to the ipsilateral puborectalis muscle.

Methods: A 60-year-old male patient with a high-grade differentiated rectal adenocarcinoma at the right side of the lower rectum invading puborectalis muscle. The proposed operation consists of a combination of extralevator abdomino-perineal excision (ELAPE), intersphicteric resection (ISR), and low anterior resection (LAR) since it resects the ipsilateral to tumor levator ani muscle (LAM) from its attachment at the internal obturator fascia and the deep part of ipsilateral external anal sphincter (EAS), while the distal part of dissection is completed in the intersphincteric space taking out the internal anal sphincter (IAS). At the contralateral side of the tumor, the dissection plane follows the classic route of LAR.

Results: Pathology proved the oncologic adequacy of resection. MRI at the fourth postoperative week showed clearly the right aspect of anorectal junction free of tumor. Anorectal manometry revealed a fair anorectal function which is in accordance with the findings of clinical assessment of patient after restoring large bowel continuity (post-op Wexner score, 7).
\end{abstract}

Conclusion: This is the first case of the open HLE that seems to be a good alternative compared to ELAPE or conventional APR, as it offers oncologic adequacy and a fair anorectal function.

Keywords: Rectal cancer, Hemilevator excision, Anorectal function, Sphincter saving

\section{Background}

The treatment of cancer of the rectal lower third has been a challenging issue over time. Back in 1908, Ernest Miles first described the abdomino-perineal excision (APE) [1]. Even after 110 years, this technique remains the standard choice for low rectal cancers (mainly found up to $5 \mathrm{~cm}$ from the anal verge) according to the ESMO guidelines for rectal cancer [2]. However, in terms of the oncologic outcome, it was found that this technique is not so effective [3]. In order to address this problem, a new technique was later described; the extralevator abdomino-perineal

\footnotetext{
* Correspondence: tsiaoussis@uoc.gr

${ }^{3}$ Laboratory of Anatomy-Histology-Embryology, Medical School of Heraklion, University of Crete, Heraklion, Greece

Full list of author information is available at the end of the article
}

excision (ELAPE). ELAPE provides a cylindrical specimen in order to decrease the risk of involved circumferential resection margins (CRM) and to reduce the risk of intraoperative tumor perforation. However, both of them bare a major drawback: the patient ends up with a permanent colostomy. For this reason, another technique was proposed, the intersphicteric resection (ISR) [4]. This technique is applicable for the resection of low rectal tumors that do not invade the external sphincter and the oncologic results are indeed acceptable [5]. The open hemilevator excision (HLE) presented here is a promising approach for patients with a tumor of the lower rectum and an ipsilateral infiltration of puborectalis muscle with no distant metastases. These patients should have an efficient anorectal function based on manometric evaluation and

(c) The Author(s). 2019 Open Access This article is distributed under the terms of the Creative Commons Attribution 4.0 International License (http://creativecommons.org/licenses/by/4.0/), which permits unrestricted use, distribution, and 
clinical assessment with the Wexner scale score for incontinence [6].

\section{Methods}

A 60-year-old male patient was referred to our hospital with a high-grade differentiated rectal adenocarcinoma. The pelvic MRI revealed a tumor at the lower rectum (its lower border was $1.5 \mathrm{~cm}$ from the anal verge) that invaded puborectalis muscle to a length of $9 \mathrm{~mm}$ on the right side. Moreover, the CT scan proved the absence of any distant metastasis. Given the tumor location and the absence of distant metastases, the patient went through manometric evaluation of anorectal function and clinical assessment with the Wexner scale score for incontinence (Table 1) before the beginning of neoadjuvant therapy in order to determine whether preservation of anal sphincteric complex could be a choice. After the completion of neoadjuvant treatment, patient was reassessed with pelvic MRI in which good response of tumor was observed. Due to the comprehensive sphincter function (pre-op Wexner score, 0), it was decided to perform a new sphincter-preserving technique without compromising the oncologic result. The patient was placed in the Lloyd-Davis position. The operation included an abdominal and a perineal phase with a total length of $5 \mathrm{~h}$ (skin to skin). For the abdominal phase, a midline incision from a point about $4 \mathrm{~cm}$ below the xiphoid to the pubis was performed in order to allow unrestricted view of the large intestine. Following Todds' avascular plane the sigmoid was mobilized and the descending colon and splenic flexure afterwards. After the dissection of the inferior mesenteric artery and vein, they were ligated with a high tie. The following step was the dissection of the rectum as guided by the embryological planes for total mesorectal excision (TME) [7]. The dissection extended to the pelvic floor consisting of the levator ani muscle (LAM). Pelvic floor dissection at the tumor's side was extended up to LAM's attachment to the internal obturator fascia, while in the contralateral side it was directed to expose puborectalis muscle close to anorectal junction. The perineal phase started with a right hemicircular incision at the level of intersphincteric line. The dissection plane followed the intersphincteric space to take out the right half of internal anal sphincter (IAS) and then moved to the right ischioanal fossa to include the deep part of ipsilateral external anal sphincter (EAS) in the specimen. The macroscopic margin from the tumor was $10 \mathrm{~mm}$. Attachment of right LAM at internal obturator fascia was cut and dissection plane integrated entering the pelvic cavity. At the left side, the hemicircular line completed in an eccentric way to preserve the main mass of the left half of IAS and to leave intact the EAS. The lateral anal canal wall was transected at the upper edge of anal columns, while entering the pelvic cavity was performed by cutting the attachment of puborectalis muscle at the lateral rectal wall. A graphic representation of the surgical planes is presented in Figs. 1 and 2. A transection of the proximal colon was achieved with a stapler device. Bowel continuity was achieved with hand-sewn colo-anal anastomosis which was protected by a diverting loop ileostomy. Total blood loss was 1.5 units $(750 \mathrm{ml})$.

\section{Results}

Postoperative route was uneventful with a total hospital stay of 6 days. Pathology proved the oncologic adequacy of the resection resulting to ypT3NxM0. According to the pathology report, no lymph nodes were harvested from the mesorectum (probably as a result of neoadjuvant therapy). MRI at the fourth postoperative week showed clearly the right aspect of anorectal junction free of tumor and the absence of ipsilateral LAM (Fig. 3a, b). The protective ileostomy was taken down 8 weeks after the surgery with no complications. The patient stayed in the hospital for 2 days and then was discharged. One month after restoring large bowel continuity, anorectal sphincter continence was re-evaluated by anorectal manometry

Table 1 Characteristics of patient's anorectal function

\begin{tabular}{|c|c|c|c|}
\hline Characteristic & Pre-operative & Post-operative & Normal values (males) \\
\hline Mean maximum anal resting pressure $(\mathrm{mmHg})$ & 68 & 50 & $59-74$ \\
\hline Instant maximum squeeze anal pressure (mmHg) & 175 & 110 & $60-220$ \\
\hline Prolonged maximum squeeze anal pressure $(\mathrm{mmHg})$ & 120 & 45 & $40-200$ \\
\hline Anal sphincter length (cm) & 3.8 & 2.4 & $2.5-5$ \\
\hline Minimum rectal volume for sustained anal relaxation (ml) & 40 & 20 & $30-60$ \\
\hline Rectal volume for first sensation (ml) & 30 & 30 & $20-110$ \\
\hline Rectal volume for permanent urge to defecate (ml) & 150 & 60 & $60-170$ \\
\hline Maximum tolerable rectal volume (ml) & 220 & 100 & $110-320$ \\
\hline Wexner score & 0 & 7 & $\begin{array}{l}0, \text { perfect continence } \\
20 \text {, major incontinence }\end{array}$ \\
\hline
\end{tabular}




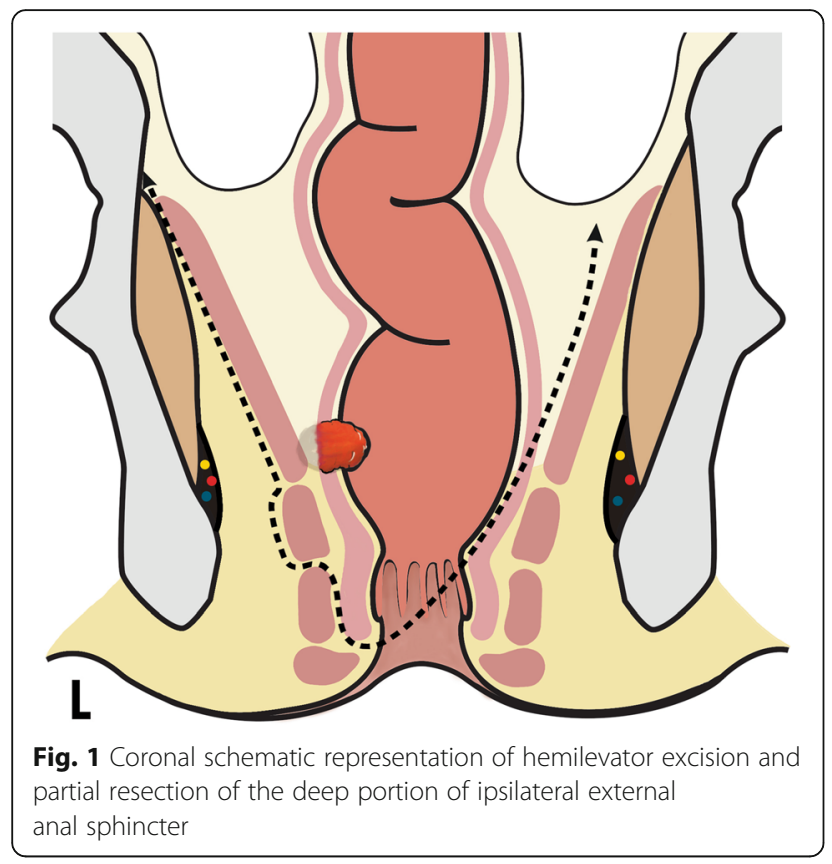

Fig. 1 Coronal schematic representation of hemilevator excision and partial resection of the deep portion of ipsilateral external anal sphincter and clinical assessment by Wexner score. A fair anorectal function was revealed which is in accordance with the findings of clinical assessment (post-op Wexner score, 7) (Table 1).

\section{Discussion}

In the earlier days of colorectal surgery for malignant tumors of the lower third of rectum, the operation of choice was the abdomino-perineal resection (APR) in which the sigmoid, the rectum, and the anus were excised leaving the levator ani muscle complex intact in both sides. In this way, the specimen resembles an hourglass due to the characteristic "waist" in the middle [8]. However, given the incomplete resection rate and the high local recurrence compared to low anterior resection of rectum (LARR) [9] colorectal surgical community has nowadays moved towards the ELAPE. The last one has proved to be superior in oncologic terms compared to conventional APR. Its superiority relies largely on the fact that apart from the sigmoid, rectum, and anus, the levator ani complex is removed as well, providing a cylindrical (waist-free) specimen, reducing by this mean, tumor involvement at circumferential resection margin. As with APR, the patient ends up with a permanent colostomy. In fact, this is the main disadvantage of both
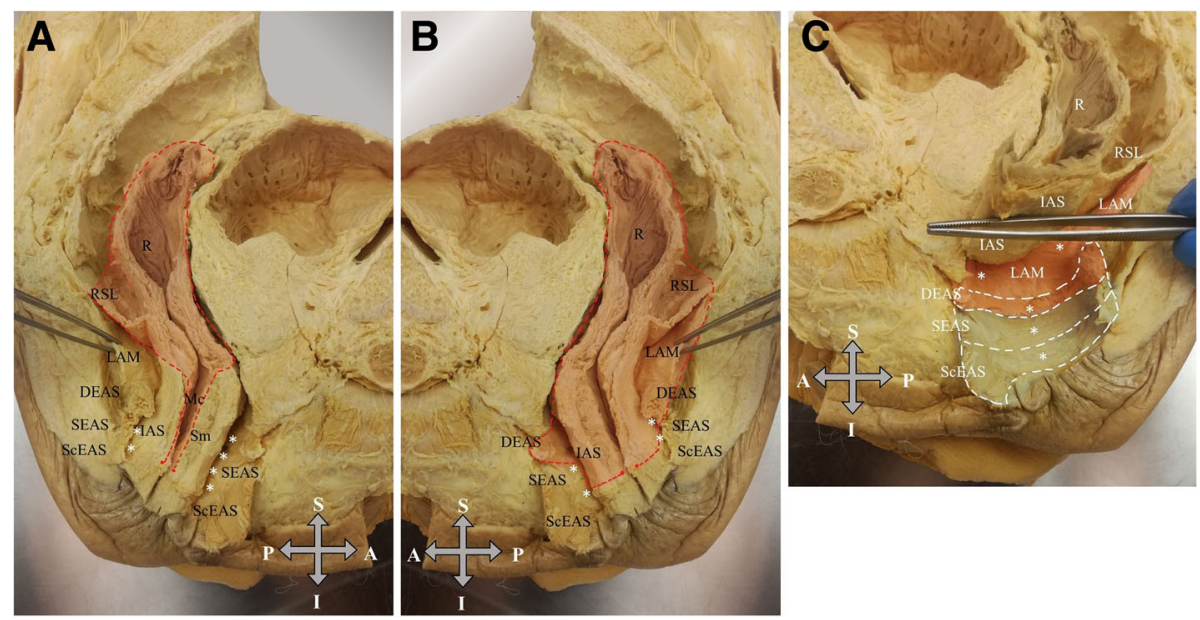

Fig. 2 a Median sagittal plane in a male cadaveric left hemipelvis. S, superior; A, anterior; P, posterior; I, inferior; R, rectum; RSL, rectosacral ligament; LAM, levator ani muscle; DEAS, deep part of the external anal sphincter; SEAS, superficial part of the external anal sphincter; ScEAS, subcutaneous part of the external anal sphincter; IAS, internal anal sphincter; Mc, the rectal mucosa; Sm, rectal submucosa. The white asterisk represents the intersphincteric space. The dashed red line represents the surgical plane. The red shade represents the excised specimen. $\mathbf{b}$ Median sagittal plane in a male cadaveric right hemipelvis. S, superior; A, anterior; P, posterior; I, inferior; R, rectum; RSL, rectosacral ligament; LAM, levator ani muscle; DEAS, deep part of the external anal sphincter; SEAS, superficial part of the external anal sphincter; ScEAS, subcutaneous part of the external anal sphincter; IAS, the internal anal sphincter. The white asterisk represents the intersphincteric space. The dashed red line represents the surgical plane. The red shade represent the excised specimen. c Median sagittal plane in a male cadaveric right hemipelvis. S, superior; A, anterior; P, posterior; I, inferior; R, rectum; RSL, rectosacral ligament; LAM, levator ani muscle; DEAS, deep part of the external anal sphincter; SEAS, superficial part of the external anal sphincter; ScEAS, subcutaneous part of the external anal sphincter; IAS, internal anal sphincter. The white asterisk represents the intersphincteric space. The dashed white line represents external anal sphincter complex. The red shade indicates the excised part of the external anal sphincter and levator ani muscle and the blue shade indicates the part of the external anal sphincter that was left intact. Courtesy of Sigmar Stelzner and Thilo Wedel, Institute of Anatomy, University of Kiel. With permission of Institute of Anatomy, University of Kiel, Germany 


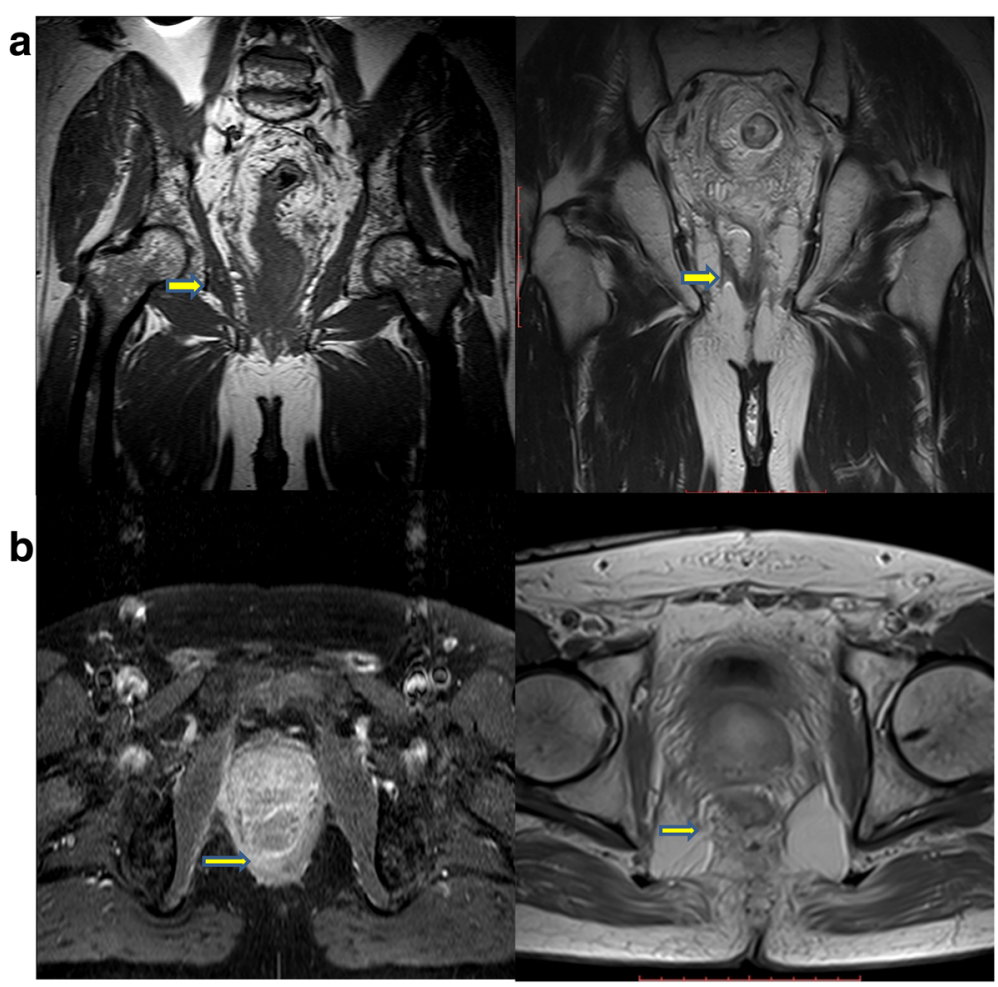

Fig. 3 a MRI coronal view of patient pelvis pre- and post operatively (left and right, respectively) (arrow shows the infiltration of right portion of levetor ani muscle by the tumor and the defect remaining after the partial excision of levator muscle ani). Preoperative MRI was performed after neoadjuvant treatment (seventh week). b MRI axial view of the same patient's area of interest

Table 2 Summary of the current trends in surgical procedures for low rectal cancers

\begin{tabular}{|c|c|c|c|c|}
\hline Operation & Technical description & Indication & Disadvantages & Reference \\
\hline $\begin{array}{l}\text { Abdomino perineal } \\
\text { resection (APR) }\end{array}$ & $\begin{array}{l}\text { Sigmoid, rectum, and anus are excised sparing } \\
\text { the levator ani muscles complex (hourglass-like } \\
\text { specimen) }\end{array}$ & $\begin{array}{l}\text { Lesions at the lower third of } \\
\text { the rectum }\end{array}$ & $\begin{array}{l}\text { Poor oncologic outcome, } \\
\text { permanent colostomy }\end{array}$ & $\begin{array}{l}\text { Hussain } \\
\text { et al. [8] }\end{array}$ \\
\hline $\begin{array}{l}\text { Extralevator abdomino- } \\
\text { perineal excision (ELAPE) }\end{array}$ & $\begin{array}{l}\text { APR }+ \text { excision of the levator ani muscles } \\
\text { complex (cylindrical specimen) }\end{array}$ & $\begin{array}{l}\text { Lesions at the lower third of } \\
\text { the rectum }\end{array}$ & Permanent colostomy & $\begin{array}{l}\text { Carpelan } \\
\text { et al. [17] }\end{array}$ \\
\hline $\begin{array}{l}\text { Intersphicteric resection } \\
\text { (ISR) }\end{array}$ & $\begin{array}{l}\text { Surgical plane in the intersphicteric space, } \\
\text { dissection of the internal anal sphincter, saving } \\
\text { the external sphincter }\end{array}$ & $\begin{array}{l}\text { - Lesions at the lower third of } \\
\text { the rectum that do not } \\
\text { involve the levator ani } \\
\text { muscles } \\
\text { - Good pre-operative sphinc- } \\
\text { ter function and continence }\end{array}$ & $\begin{array}{l}\text { May not be suitable for } \\
\text { patients that have } \\
\text { undergone neoadjuvant } \\
\text { treatment }\end{array}$ & $\begin{array}{l}\text { Schiessel } \\
\text { et al. [4] }\end{array}$ \\
\hline $\begin{array}{l}\text { Subtotal intersphincteric } \\
\text { resection/partial external } \\
\text { sphincteric resection }\end{array}$ & ISR + partial external anal sphincter resection & $\begin{array}{l}\text { - Lesions of the lower third of } \\
\text { the rectum invading part of } \\
\text { the external anal sphincter } \\
\text { - Good pre-operative sphinc- } \\
\text { ter function and continence }\end{array}$ & $\begin{array}{l}\text { Not applicable for lesions } \\
\text { invading the levator ani } \\
\text { muscle }\end{array}$ & $\begin{array}{l}\text { Mukai } \\
\text { et al. [10] }\end{array}$ \\
\hline $\begin{array}{l}\text { Hemilevator excision } \\
\text { (HLE) }\end{array}$ & $\begin{array}{l}\text { Resection of the levator ani muscle, the deep } \\
\text { part of external anal sphincter and the internal } \\
\text { sphincter ipsilaterally. The contralateral ones are } \\
\text { preserved }\end{array}$ & $\begin{array}{l}\text { - Lesions at the lower third of } \\
\text { the rectum involving the } \\
\text { levator ani muscle in one } \\
\text { side } \\
\text { - Good pre-operative sphinc- } \\
\text { ter function and continence }\end{array}$ & $\begin{array}{l}\text { Not applicable for cancers } \\
\text { circumferentially infiltrating } \\
\text { levator ani complex }\end{array}$ & $\begin{array}{l}\text { Noh et al. } \\
{[11]}\end{array}$ \\
\hline
\end{tabular}


operations affecting patients' quality of life. In an attempt to reduce the frequency of permanent colostomy in low rectal cancer surgery a better selection of patients has been suggested. So, in cases with very low rectal lesions, no involvement of the external anal sphincter or the levator ani muscle complex, and adequate preoperative sphincter function and continence, ISR is preferred as it preserves anal sphincteric function to some extent. This is achieved by entering the intersphicteric space and dissecting the internal from the external anal sphincters, leaving the later almost intact [4]. Attempts for function-preserving procedures with partial external anal sphincter resection have been described in cases with external anal sphincter infiltration [10]. Moreover, in a special sub-group with unilateral puborectalis muscle infiltration and adequate sphincteric function, HLE was proposed as an attempt to keep anorectal function and achieve oncologic adequacy. A comprehensive summary of the current surgical procedures for low rectal cancer is presented in Table 2. Noh et al. proved that robotic/laparoscopic HLE yield oncologic results comparable to those of a standard ELAPE, while offering the patient the unparalleled advantage of avoiding a permanent colostomy [11]. According to them, an open approach is not feasible since the surgeon lacks of a clear view of the surgical field. Since the open approach still remains the standard of care in rectal cancer surgery, we tried to perform HLE by this way. Herein, we show that an open approach not only is feasible but also can potentially be served as a promising alternative for laparoscopic or robotic HLE since the latter two forms are not widely popularized among the surgical community yet. Moreover, being able to perform the open approach is important even among those surgeons who are trained on the laparoscopic and/or robotic techniques because knowing this alternative would allow them to overcome difficulties that would require the conversion of the surgery (from laparoscopic to an open one) with minimum oncologic cost for the patient. However, laparoscopic and robotic procedures overcome the open one concerning the enhanced vision and appreciation of the field $[12,13]$. It is reasonable some concerns to be raised regarding the oncologic radicality since anatomic borders among LAM, PRM and the deep part of the EAS are not very clear [14]. Indeed, the heated debate regarding the anatomy of anal canal dates back to 1897. At that time, it was identified that some muscle fibers of the "pubococcygeus," instead of inserting into the coccyx, loop around the rectum, continue on to the opposite side and thus form a different muscle, the PRM. Since then, the EAS is perceived as a three-part structure with the PRM being part of the LAM; PRM is located just below the LAM and EAS extends down. The very close relation of the deep part of the EAS and PRM has led some authors to consider them as one muscle $[15,16]$. Baring this debate in mind, in order to enhance the oncologic safety of the procedure, the deep part of ipsilateral to tumor EAS is included in the surgical specimen. Moreover, a macroscopic margin $10 \mathrm{~mm}$ of the transection line from the lower border of tumor ensures the oncologic adequacy further. The oncologic value of the open approach seems to be equal to that of the other approaches, as proved by the pathology of the specimen and the MRI at the fourth post-operative week that shows clearly the right aspect of anorectal junction free of tumor and the absence of ipsilateral LAM (Fig. 2a, b). The major advantage of the open procedure is the maintenance of continence, as proved by the postoperative clinical assessment of patient after restoring large bowel continuity (post-op Wexner score, 7) and the anorectal manometry findings (which in our case, revealed a fair anorectal function). In fact, the efficiency of the operated sphincter is acceptable since only a part of the deep portion of the EAS is removed. Preservation of internal anal sphincter at the contralateral to tumor side might also add to the whole sphincteric function and particularly at rest and during the sleep.

\section{Conclusions}

This is the first attempt at Greece to perform a technique which targets the saving of anal sphincter for very low rectal cancers with extension to the puborectalis muscle. This is the first procedure with removal of puborectalis muscle and partial excision of external sphincter with preservation of anal function. This innovative procedure requires full knowledge of pelvic anatomy. The surgical team must have experience to the standard TME. This procedure is the hope for a life without colostomy for patients with these tumors. Undoubtedly, a larger number of cases is demanded to draw firm conclusions since we have to take into account that anatomic characteristics such as gender, body mass index, etc. might affect the feasibility of the procedure.

\section{Abbreviations \\ APE: Abdomino-perineal excision; CRM: Circumferential resection margins; EAS: External anal sphincter; ELAPE: Extralevator abdomino-perineal excision; HLE: Hemilevator excision; IAS: Internal anal sphincter; ISR: Intersphicteric resection; LAM: Levator ani muscle; LAR: Low anterior resection; \\ PRM: Puborectalis muscle; TME: Total mesorectal excision}

\section{Acknowledgements}

The authors would like to thank Professor Dr. Med. T. Wedel for providing the cadaveric pictures and declare to have no rights on them. All copyrights of the cadaveric pictures remain to the Institute of Anatomy, University of Kiel, Germany, for any future use by them.

\section{Authors' contributions}

TMS and JT contributed to the conception, design, and critical revision of the manuscript for important intellectual content. GP and TKN drafted the 
manuscript. $K L, C T$, and $G B$ critically revised the manuscript for important intellectual content. All authors read and approved the final manuscript.

\section{Funding}

Not applicable

\section{Availability of data and materials}

The data that support the findings of this study are available from John Tsiaoussis, but restrictions apply to the availability of these data, which were used under license for the current study, and so are not publicly available. Data are however available from the authors upon reasonable request and with the permission of John Tsiaoussis

\section{Ethics approval and consent to participate}

Not applicable

\section{Consent for publication}

Not applicable

\section{Competing interests}

The authors declare that they have no competing interests.

\section{Author details}

'Consultant General Surgeon Surgical Department, Agioi Anargyroi General and Oncologic Hospital of Kifisia, National \& Kapodistrian University of Athens, University of Athens, Athens, Greece. ${ }^{2}$ Surgical Department, Agioi Anargyroi General and Oncologic Hospital of Kifisia, University of Athens, Athens, Greece. ${ }^{3}$ Laboratory of Anatomy-Histology-Embryology, Medical School of Heraklion, University of Crete, Heraklion, Greece. ${ }^{4}$ Oncology Pathology Department, Agioi Anargyroi General and Oncologic Hospital of Kifisia, Athens, Greece. ${ }^{5}$ Radiology Department, Konstantopouleio General Hospital, Athens, Greece. ${ }^{6}$ Surgical Department, Agioi Anargyroi General and Oncologic Hospital of Kifisia, National \& Kapodistrian University of Athens, University of Athens, Athens, Greece.

Received: 22 April 2019 Accepted: 22 July 2019

Published online: 02 August 2019

\section{References}

1. Ernest Miles W. A method of performing abdomino-perineal excision for carcinoma of the rectum and of the terminal portion of the pelvic colon. Lancet. 1908;172(4451):1812-3 Available from: http://linkinghub.elsevier. com/retrieve/pii/S0140673600990767. Cited 2018 Jul 8.

2. Glynne-Jones R, Wyrwicz L, Tiret E, Brown G, Rödel C, Cervantes A, et al. Rectal cancer: ESMO clinical practice guidelines for diagnosis, treatment and followup. Ann Oncol. 2018;mdy161. https://doi.org/10.1093/annonc/mdy161.

3. Heald RJ, Smedh RK, Kald A, Sexton R, Moran BJ. Abdominoperineal excision of the rectum--an endangered operation. Norman Nigro Lectureship. Dis Colon Rectum. 1997:40(7):747-51 Cited 2018 Jul 10. http://www.ncbi.nlm. nih.gov/pubmed/9221846.

4. Schiessel R, Karner-Hanusch J, Herbst F, Teleky B, Wunderlich M. Intersphincteric resection for low rectal tumours. Br J Surg. 1994:81(9):1376-8 Cited 2018 Jul 10. Available from: http://www.ncbi.nlm.nih.gov/pubmed/7953423.

5. Akasu T, Takawa M, Yamamoto S, Fujita S, Moriya Y. Incidence and patterns of recurrence after intersphincteric resection for very low rectal adenocarcinoma. J Am Coll Surg. 2007;205(5):642-7 Cited 2018 Jul 10. Available from: http://linkinghub.elsevier.com/retrieve/pii/S1072 751507007636

6. Vaizey CJ, Carapeti E, Cahill JA, Kamm MA. Prospective comparison of faecal incontinence grading systems. Gut. 1999;44(1):77-80 Cited 2018 Jul 21. Available from: http://www.ncbi.n/m.nih.gov/pubmed/9862829.

7. Pechlivanides G, Gouvas N, Tsiaoussis J, Tzortzinis A, Tzardi M, Moutafidis M, et al. Lymph node clearance after total mesorectal excision for rectal Cancer: laparoscopic versus open approach. Dig Dis. 2007;25(1):94-9 Cited 2019 Apr 2. Available from: https://www.karger.com/Article/FullText/99176.

8. Hussain A, Mahmood F, Torrance ADW, Clarke H, Howitt C, Dawson R. Oncological outcomes of abdominoperineal resection for the treatment of low rectal cancer: a retrospective review of a single UK tertiary centre experience. Ann Med Surg. 2018:34:28-33 Cited 2019 Jan 28. Available from: https:// linkinghub.elsevier.com/retrieve/pii/S2049080118301225.
9. Perez D, Melling N, Biebl M, Reeh M, Baukloh J-K, Miro J, et al. Robotic low anterior resection versus transanal total mesorectal excision in rectal cancer: a comparison of 115 cases. Eur J Surg Oncol. 2018;44(2):237-42 Cited 2019 Jul 11. Available from: http://www.ncbi.n/m.nih.gov/pubmed/29249592.

10. Mukai M. Anal function-preserving subtotal intersphincteric resection/partial external sphincteric resection with hybrid 2-port hand-assisted laparoscopic surgery (Mukai's operation) for very low stage I rectal cancer: a case report. Oncol Lett. 2011; Cited 2019 Jul 11. Available from: http://www.spandidospublications.com/10.3892/ol.2011.327.

11. Noh GT, Han J, Cheong C, Han YD, Kim NK. Novel anal sphincter saving procedure with partial excision of levator-ani muscle in rectal cancer invading ipsilateral pelvic floor. Ann Surg Treat Res. 2017;93(4):195-202. Cited 2018 Jul 25. Available from: https://www.ncbi.nlm.nih.gov/pubmed/2 9094029. https://doi.org/10.4174/astr.2017.93.4.195

12. Gouvas N, Tsiaoussis J, Pechlivanides G, Zervakis N, Tzortzinis A, Avgerinos C, et al. Laparoscopic or open surgery for the cancer of the middle and lower rectum short-term outcomes of a comparative non-randomised study. Int J Color Dis. 2009;24(7):761-9 Cited 2018 Dec 12. Available from: http://www. ncbi.nlm.nih.gov/pubmed/19221764.

13. Gouvas N, Tsiaoussis J, Pechlivanides G, Tzortzinis A, Dervenis C, Avgerinos C, et al. Quality of surgery for rectal carcinoma: comparison between open and laparoscopic approaches. Am J Surg. 2009:198(5):702-8 Cited 2018 Dec 12. Available from: http://www.ncbi.n/m.nih.gov/pubmed/19306987.

14. Tsukada $Y$, Ito M, Watanabe $K$, Yamaguchi K, Kojima M, Hayashi R, et al. Topographic anatomy of the anal sphincter complex and levator ani muscle as it relates to intersphincteric resection for very low rectal disease. Dis Colon Rectum. 2016;59(5):426-33 Cited 2018 Oct 8. Available from: http:// insights.ovid.com/crossref?an=00003453-201605000-00010.

15. Wallner C. Is the puborectalis muscle part of the levator ani muscle? Dis Colon Rectum. 2008;51(7):1165-6 author reply 1167. Cited 2019 Jan 31. Available from: http://www.ncbi.n/m.nih.gov/pubmed/18454294.

16. Shafik A. A new concept of the anatomy of the anal sphincter mechanism and the physiology of defecation: mass contraction of the pelvic floor muscles. Int Urogynecol J Pelvic Floor Dysfunct. 1998;9(1):28-32 Cited 2019 Jan 31. Available from: http://www.ncbi.n/m.nih.gov/pubmed/9657175.

17. Carpelan A, Karvonen J, Varpe P, Rantala A, Kaljonen A, Grönroos J, et al. Extralevator versus standard abdominoperineal excision in locally advanced rectal cancer: a retrospective study with long-term follow-up. Int J Color Dis. 2018;33(4):375-81 Cited 2019 Jul 11. Available from: http://www.ncbi.nlm. nih.gov/pubmed/29445870.

\section{Publisher's Note}

Springer Nature remains neutral with regard to jurisdictional claims in published maps and institutional affiliations.

Ready to submit your research? Choose BMC and benefit from:

- fast, convenient online submission

- thorough peer review by experienced researchers in your field

- rapid publication on acceptance

- support for research data, including large and complex data types

- gold Open Access which fosters wider collaboration and increased citations

- maximum visibility for your research: over $100 \mathrm{M}$ website views per year

At BMC, research is always in progress.

Learn more biomedcentral.com/submissions 